\title{
Neurotransmitter Regulation of Cellular Activation and Neuropeptide Gene Expression in the Paraventricular Nucleus of the Hypothalamus
}

\author{
Rebecca L. Cole and Paul E. Sawchenko \\ Laboratory of Neuronal Structure and Function, The Salk Institute for Biological Studies and Foundation for Medical \\ Research, La Jolla, California 92037
}

Norepinephrine (NE), glutamate (Glu), and GABA have been identified as important neurotransmitters governing neuroendocrine mechanisms represented in the paraventricular nucleus of the hypothalamus (PVH). Microinjection studies were used to compare the efficacy of these transmitter mechanisms in stimulating PVH output neurons. Local administration of NE provoked an increase in plasma corticosterone levels and Fos induction in the both the parvocellular and magnocellular divisions of the nucleus. This treatment also stimulated a robust increase in corticotropin-releasing factor (CRF) heteronuclear (hn) RNA in the parvocellular PVH and a more subtle, although reliable, increase in arginine vasopressin (AVP) hnRNA in this same compartment. Local administration of the $\mathrm{GABA}_{\mathrm{A}}$ receptor antagonist bicuculline methiodide (BMI) resulted in increased plasma corticosterone and, in contrast to NE treatment, Fos induction limited primarily to the parvocellular PVH.
BMI elicited marked increases in both $\mathrm{CRH}$ and AVP hnRNAs within the parvocellular division of the nucleus. Over a wide range of concentrations, Glu failed to produce reliable increases in corticosterone secretion and induced only weak activational responses limited primarily to non-neurosecretory regions of the $\mathrm{PVH}$. Local Glu administration did, however, provoke Fos induction in identified GABAergic neurons immediately adjoining the $\mathrm{PVH}$, suggesting that the muted response to Glu may be a consequence of concurrent activation of local inhibitory interneurons. These results support a differential involvement of adrenergic, glutamatergic and GABAergic mechanisms in regulating neurosecretory populations of the $\mathrm{PVH}$ and suggest that involvement of local circuit neurons must be carefully considered in the interpretation of microinjection studies.

Key words: corticotropin-releasing factor; GABA; glutamate; norepinephrine; stress; vasopressin
The paraventricular hypothalamic nucleus $(\mathrm{PVH})$ is a key site for marshaling integrated and adaptive responses to stress. The PVH houses (1) parvocellular neurosecretory neurons expressing corticotropin-releasing factor $(\mathrm{CRF})$ for the initiation of the endocrine (pituitary-adrenal) arm of the generalized stress response, (2) neurons projecting to central autonomic cell groups, including sympathetic preganglionics that constitute the neural arm of the stress response, and (3) magnocellular neurosecretory cells that release oxytocin and arginine vasopressin (AVP) from the posterior pituitary in response to more specific physiological demands (Swanson and Sawchenko, 1983). The advent of immediate-early gene-based functional mapping (Morgan and Curran, 1991) has made it clear that these populations can be recruited differentially, with the parvocellular CRF population being activated nearly invariantly in response to acute stress (Ceccatelli et al., 1989; Chan et al., 1993).

Such approaches have also facilitated efforts to define extended circuitries underlying the recruitment of PVH effector neurons to particular insults. Although candidate afferent mediators of PVH responses have been identified in some stress models, less attention has been directed toward identifying neurotransmitter sys-

\footnotetext{
Received June 7, 2001; revised Oct. 4, 2001; accepted Oct. 24, 2001.

This work was supported by National Institutes of Health Grant NS-21182. We thank Drs. A. Ericsson, T. G. Sherman, and A. Tobin for generously providing plasmids and Dr. C. Rivier for RIAs. We gratefully acknowledge the assistance of Carlos Arias (technical), Kris Trulock (graphic-photographic), Belle Wamsley (editorial), and Eugene Brandon for helpful comments on this manuscript.

Correspondence should be addressed to Dr. P. E. Sawchenko, The Salk Institute, 10010 N. Torrey Pines Road, La Jolla, CA 92037. E-mail: sawchenko@salk.edu. Copyright (C) 2002 Society for Neuroscience $0270-6474 / 02 / 220959-11 \$ 15.00 / 0$
}

tems involved in stressor-specific regulation of $\mathrm{PVH}$ compartments. The principal ones implicated in PVH control include norepinephrine (NE), GABA, and glutamate (Glu). The PVH receives a dense catecholaminergic innervation from the caudal medulla, which serves mainly to relay visceral sensory information (Sawchenko and Swanson, 1981; Cunningham and Sawchenko, 1988). Accordingly, these pathways have been implicated in mediating the effects of systemic stressors, such as hemorrhage and immune challenges (Plotsky et al., 1989; Ericsson et al., 1994; Chan et al., 2001) (see also Plotsky, 1987). GABA is the principal inhibitory neurotransmitter in the PVH (Decavel and van den Pol, 1990). GABAergic inputs originate mainly from local hypothalamic sources and are thought to impart limbic and cortical influences on PVH mechanisms (Roland and Sawchenko, 1993; Boudaba et al., 1996; Herman and Cullinan, 1997). Finally, glutamate has been suggested as the dominant excitatory neurotransmitter in neuroendocrine regulation (van den Pol et al., 1990; van den Pol and Trombley, 1993; Brann, 1995; Oliver et al., 1996), although neither the origins of glutamatergic inputs nor their role in initiating hypothalamo-pituitary-adrenal (HPA) responses have been defined clearly (Costa et al., 1992; Patchev et al., 1994; Oliver et al., 1996). One goal of the present study was to compare the effects of manipulating these transmitter systems on $\mathrm{PVH}$ regulatory mechanisms, focusing on substrates for HPA control.

Establishing functional linkages between circuitry, transmitters, and target neuron effects is complicated by the fact that PVH cell types may use multiple effector molecules. Thus, although CRF provides a neurochemical signature for HPA-related hy- 
pophysiotropic neurons, it does not act alone in this regard. These neurons can synthesize additional peptides, notably AVP, which synergize with CRF to determine pituitary-adrenal output (Gillies et al., 1982; Rivier and Vale, 1983; Hauger and Aguilera, 1993). AVP is regulated more dynamically than CRF in this context and is generally viewed as the major determinant of situation-specific drive on the axis (Antoni, 1993; Kovács et al., 2000). Recent analyses using probes to intronic sequences to monitor transcriptional activation directly (Herman et al., 1991, 1992) describe distinct time courses of stress-induced activation of the expression of these genes, with elevations in primary CRF and AVP transcripts occurring at 5-30 and 60-120 min, respectively (Imaki et al., 1995; Kovács and Sawchenko, 1996; Ma et al., 1997). This provides a framework for examining how regulatory influences participate in this differential control, and selective activation of CRF transcription in response to local $\mathrm{NE}$ injection has been reported (Itoi et al., 1999). A second objective of the present study was to confirm and extend this analysis.

Parts of this work have been published previously in abstract form (Cole and Sawchenko, 1998).

\section{MATERIALS AND METHODS}

Animals and treatment paradigms. Adult male Sprague Dawley albino rats (250-300 gm) were used in all experiments. Animals were housed in a colony room under controlled temperature and humidity, with food and water available ad libitum. Lights were on between 7:00 A.M. and 7:00 P.M. The rats were adapted to handling for at least $3 \mathrm{~d}$ before any treatment. In all experiments, group sizes were $n=4-8$. All protocols were approved by the Institutional Animal Care and Use Committee of the Salk Institute.

Intracerebral microinjection. Rats were anesthetized and implanted with unilateral 24 ga guide cannulas aimed to terminate $1 \mathrm{~mm}$ dorsal to the PVH. Coordinates used for PVH microinjections were $1.8 \mathrm{~mm}$ posterior to bregma, $0.5 \mathrm{~mm}$ lateral to the midline, and $5.9 \mathrm{~mm}$ ventral from the dura. After $7 \mathrm{~d}$ recovery, during which time animals were handled and subjected to daily mock injections, rats were challenged with drug or vehicle injections via 30 ga injectors that extended $1.0 \mathrm{~mm}$ beyond the tip of the guide. All drugs were administered in $200 \mathrm{nl}$ of sterile pyrogen-free saline. Drug doses were based on the range of concentrations known to elicit relevant physiological responses in previous microinjection studies (Leibowitz, 1978; Lipski et al., 1988; Itoi et al., 1994; Huhman et al., 1995; Soltis et al., 1997; Chan et al., 1998). Groups of animals received $1 \mathrm{nmol}$ of L-glutamate (Sigma, St. Louis, MO), 100 pmol of bicuculline methiodide (BMI) (Fluka, Buchs, Switzerland), 25 nmol of norepinephrine bitartrate (Sigma), or saline vehicle. After injections, animals were returned to their home cages, in which they remained undisturbed until being killed 20 or 90 min later. These time points were selected to approximate those at which peak stress-induced elevations of CRF heteronuclear (hn) RNA (20 min) or both AVP hnRNA and Fos-immunoreactivity (IR) $(90 \mathrm{~min}$ ) have been described within the parvocellular division of the PVH.

To determine the approximate extent of diffusion after microinjection, $200 \mathrm{nl}$ of $\left[{ }^{3} \mathrm{H}\right] \mathrm{NE}$ (DuPont NEN, Boston, MA) was injected into the $\mathrm{PVH}$ of a separate group of animals. $\left[{ }^{3} \mathrm{H}\right] \mathrm{NE}(0.1 \mu \mathrm{Ci})$ was added to cold NE to make up a $50 \mathrm{nmol} / 0.1 \mu \mathrm{l}$ solution.

Blood sampling and plasma corticosterone assay. Rats bearing cerebral guide cannulas were implanted with indwelling jugular venous catheters $2 \mathrm{~d}$ before experimentation. Catheters were made using polyethylene-50 tubing with SILASTIC (Dow Corning, Corning, NY) tips that terminated near the atrium and were exteriorized in an interscapular position. Testing was performed in freely moving rats in their home cages starting at 9:00 A.M., before the circadian increase in plasma corticosterone levels. Repeated blood samples $(100 \mu \mathrm{l})$ were taken before and at 5, 15, 30,60 , and $90 \mathrm{~min}$ after central injections of drug or vehicle administered as described above. Samples were collected in chilled tubes containing 2 $\mu 1$ of $20 \%$ EDTA and centrifuged, and plasma was stored at $-20^{\circ} \mathrm{C}$ until assay. Plasma corticosterone was measured by radioimmunoassay (ImmuChem; ICN Biomedicals, Cleveland, $\mathrm{OH}$ ), using a rabbit antiserum raised against corticosterone-3-carboxymethyloxime:BSA. The sensitivity of the assay is $5 \mathrm{ng} / \mathrm{ml}$; intra-assay and interassay coefficients of variation are $<10.3$ and $<7.2 \%$, respectively.
Perfusion and tissue processing. Animals were perfused under chloral hydrate anesthesia $(350 \mathrm{mg} / \mathrm{kg}$, i.p.) via the ascending aorta with saline, followed by $500 \mathrm{ml}$ of ice-cold $4 \%$ paraformaldehyde in $0.1 \mathrm{M}$ borate buffer at $\mathrm{pH} 9.5$, delivered over $20 \mathrm{~min}$. Brains were post-fixed in the perfusate for $2 \mathrm{hr}$ and then stored overnight in potassium PBS with $10 \%$ sucrose at $4^{\circ} \mathrm{C}$. Multiple series of $30-\mu \mathrm{m}$-thick frozen sections, collected at $150 \mu \mathrm{m}$ intervals, were cut on a sliding microtome and collected into cryoprotectant, in which they were stored at $-20^{\circ} \mathrm{C}$ until use.

Immunohistochemistry. Fos-IR was localized using a polyclonal antiserum raised in rabbit against synthetic human Fos (amino acid positions 3-15), at a dilution of 1:5000 (Santa Cruz Biotechnology, Santa Cruz, CA). Immunohistochemistry was performed using a conventional avidin-biotin immunoperoxidase protocol (Sawchenko et al., 1990) and Vectastain Elite reagents (Vector Laboratories, Burlingame, CA). Tissue was pretreated with hydrogen peroxide $(0.3 \%)$ before addition of the primary antibody to squelch endogenous peroxidase activity in the tissue. The diaminobenzidine reaction was amplified using nickel ammonium sulfate.

To compare the distribution and relative strength of activational responses to drug treatments, counts of the number of Fos-IR cells in cytoarchitectonically defined subregions of the PVH (Swanson and Kuypers, 1980) were generated in complete series of sections through the caudal PVH and corrected for double-counting errors (Abercrombie, 1946).

Hybridization histochemistry. Hybridization histochemistry was performed using $\left[{ }^{35} \mathrm{~S}\right] \mathrm{UTP}$ (DuPont NEN) labeled antisense cRNA probes. The AVP hnRNA probe was transcribed from a $700 \mathrm{bp} P V U I I$ fragment of intron I of the rat vasopressin gene subcloned into pGEM3 (Herman et al., 1991). The CRF hnRNA probe was transcribed from a $500 \mathrm{bp}$ PVUII fragment of the single intron in the CRF gene from a rat genomic CRF clone, subcloned into pBluescript (Dr. A. Ericsson, The Salk Institute). The identity and specificity of each probe has been established by partial sequence and/or Northern blot analysis, and each yields hybridization patterns in accord with available evidence. Sense strand probes labeled to similar specific activities produced no clear positive hybridization signals in the PVH or elsewhere in brain (data not shown).

Hybridization and autoradiographic techniques were modified as described previously (Simmons et al., 1989). Tissue sections were mounted on poly-L-lysine-coated slides, post-fixed with formalin for $30 \mathrm{~min}$, digested with $10 \mu \mathrm{g} / \mathrm{ml}$ proteinase $\mathrm{K}$, acetylated with $0.25 \%$ acetic anhydride, and dehydrated. Probes were labeled to specific activities on the order of $1-3 \times 10^{9} \mathrm{dpm} / \mu \mathrm{g}$ and applied to the slide at concentrations of $\sim 10^{7} \mathrm{cpm} / \mathrm{ml}$, overnight at $56-58^{\circ} \mathrm{C}$ in a solution containing $50 \%$ formamide, $0.3 \mathrm{~m} \mathrm{NaCl}, 10 \mathrm{~mm}$ Tris, pH 8.0, 1 mm EDTA, 0.05\% tRNA, 10 $\mathrm{mm}$ dithiothreitol, $1 \times$ Denhardt's solution, and $10 \%$ dextran sulfate, after which they were treated with $20 \mu \mathrm{g} / \mathrm{ml}$ ribonuclease A for $30 \mathrm{~min}$ at $37^{\circ} \mathrm{C}$ and washed in $15 \mathrm{~mm} \mathrm{NaCl} / 1.5 \mathrm{~mm}$ sodium citrate at $65-85^{\circ} \mathrm{C}$. Slides were then dehydrated and exposed to x-ray films ( $\beta$-max; Eastman Kodak, Rochester, NY) for 1-2 d. They were then coated with Kodak NTB-2 liquid emulsion, and exposed at $4^{\circ} \mathrm{C}$ for a length of time determined by the strength of signal on film. CRH hnRNA slides were exposed for $45 \mathrm{~d}$. AVP hnRNA slides were exposed for $21 \mathrm{~d}$ to optimize the localization of AVP hnRNA in the parvocellular division of the PVH. Because of the long exposure time, AVP hnRNA in the magnocellular division of the PVH is beyond the linear range of the assay and could not be quantified in the material used in these experiments. Slides were developed with Kodak D-19 and fixed with Kodak rapid fixer.

Combined immunohistochemistry and hybridization histochemistry. The protocol for combining immunoperoxidase labeling with isotopic in situ hybridization involves minor modifications (Chan et al., 1993) of the procedure described by Watts and Swanson (1989). Immunolocalization of Fos-IR was combined with hybridization histochemical detection of GAD-67 mRNA. GAD-67 mRNA was localized using a ${ }^{35}$ S-labeled cRNA probe (Dr. A. J. Tobin, University of California at Los Angeles, Los Angeles, CA). Immunostaining was performed first, and the individual methods are modified as follows: (1) nonimmune (blocking) sera, potential sources of RNase contamination, were replaced with $2 \%$ heparin sulfate and $2 \%$ BSA; (2) nickel enhancement steps were eliminated from the immunostaining protocol because nickel-based reaction product does not survive the hybridization steps; (3) tissue pretreatment with hydrogen peroxide was omitted; and (4) Nissl counterstaining was omitted.

Comparisons of the ability of Glu injections to activate local GABAergic neurons were performed by counting the number of Fosimmunoreactive cells in sections through the central part of the anterior 

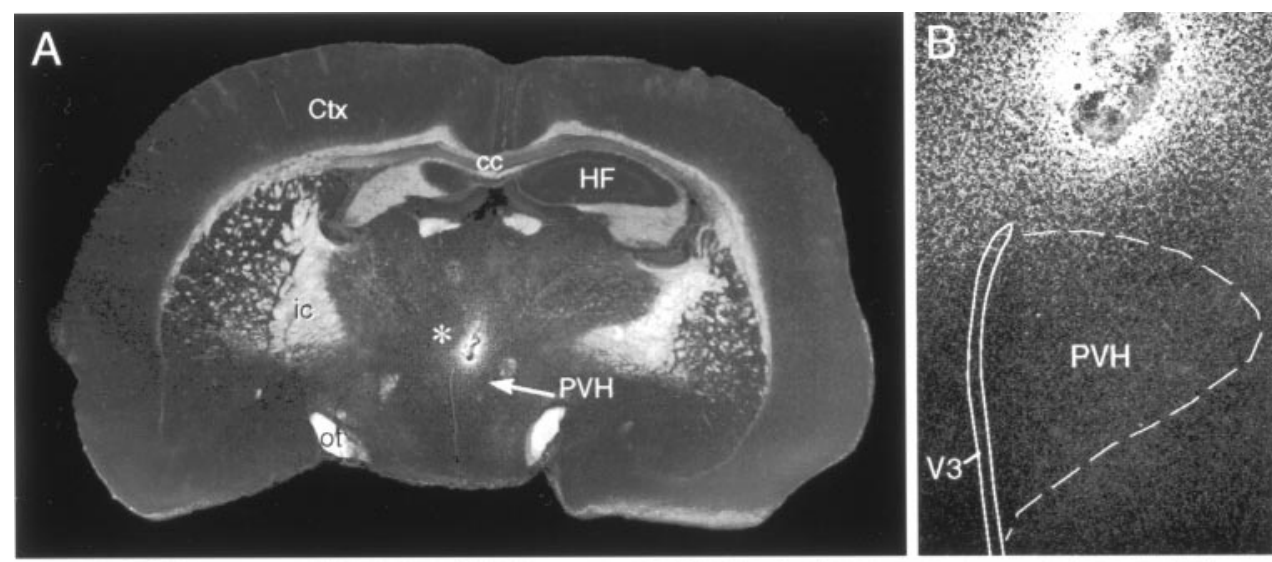

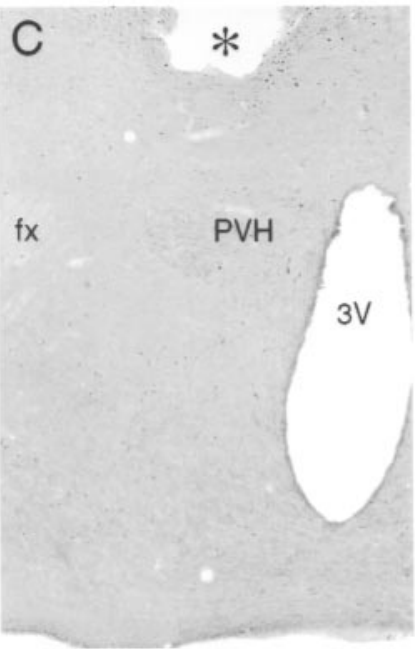

Saline

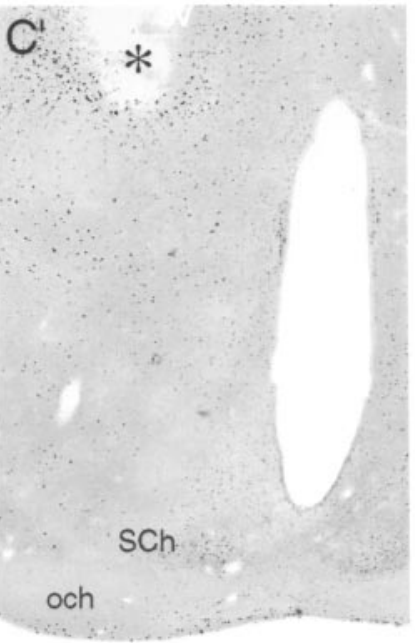

Glutamate

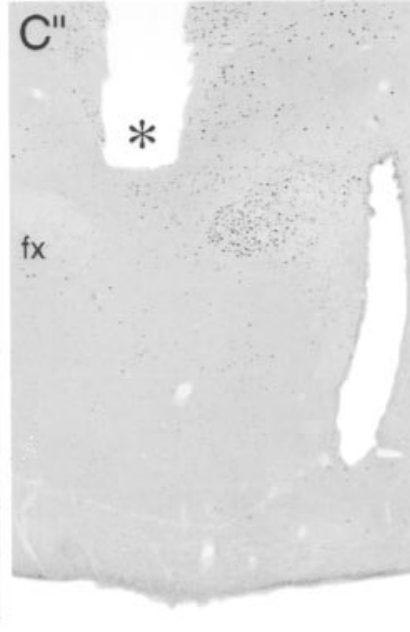

Norepinephrine
Figure 1. The extent and placement of microinjections into the PVH. $A$, Darkfield photomicrograph showing the location and extent of a microinjection of $200 \mathrm{nl}$ of $\left[{ }^{3} \mathrm{H}\right] \mathrm{NE}$ (asterisk) into the region just dorsal to the PVH (arrow). B, Enlarged view of injection site showing that the gradient of diffused injectate spreads to involve the PVH. $C$, Bright-field photomicrographs of immunoperoxidase preparations (for FosIR) to show representative microinjection cannula placements in rats injected with saline $(C)$, glutamate $\left(C^{\prime}\right)$ or norepinephrine $\left(C^{\prime \prime}\right)$. Note that the placements shown in $C$ and $C^{\prime \prime}$ are centered at the level of the mid-PVH, although the one illustrated in $C^{\prime}$ is situated more rostrally. Rats whose cannula tips were found to lay within a ventricle or $>1 \mathrm{~mm}$ from the dorsal and/or lateral margin of the PVH were excluded from analysis. Induced Fos-IR is observed as a black reaction product. Magnifications: $A, 8.5 \times ; B, 70 \times ; C, 25 \times . c c$, Corpus callosum; Ctx, cerebral cortex; $f x$, fornix; $H F$, hippocampal formation; ic, internal capsule; och, optic chiasm; ot, optic tract; SCh, suprachiasmatic nucleus. hypothalamic area of Glu- and saline-treated rats and assessing the proportion of these that were overlain by clusters of reduced silver grains whose density exceeded five times background levels, as determined by grain density counts over cell-sized areas in the thalamus. Average counts per section were generated in three sections through representative levels of the anterior hypothalamic area in each animal and then averaged again to obtain group means.

Data collection and analysis. Material to be compared was hybridized using a common batch of probe. Semiquantitative densitometric analysis of relative levels of RNAs was performed on emulsion-coated slides. Slides were coded for analysis to obscure treatment status. Densitometric analysis of autoradiographic images was performed using Macintoshdriven NIH Image software (version 1.62). The medial parvocellular subdivision of the PVH (Swanson and Kuypers, 1980) was defined from Nissl staining patterns and aligned with corresponding dark-field images of hybridized sections by redirected sampling. Analysis of AVP hnRNA is confounded by the presence of densely labeled magnocellular neurons that are scattered within the parvocellular division of the PVH. Because this can mask or dilute changes assessed using densitometric analysis, a second approach to quantification was used. This involved simply counting the number of nuclei in the medial parvocellular division of the $\mathrm{PVH}$, which contained clusters of silver grains whose density was more than five times background. Abercrombie's method (Abercrombie, 1946) was used to correct for double-counting errors. Data from all measures are expressed as mean \pm SEM and were analyzed by one-way ANOVA.

\section{RESULTS}

\section{Cannula placements}

To determine the approximate extent of diff usion after microinjection, $200 \mathrm{nl}$ of $\left[{ }^{3} \mathrm{H}\right] \mathrm{NE}$ was injected into the $\mathrm{PVH}$ in four rats (Fig. $1 A, B) \cdot\left[{ }^{3} \mathrm{H}\right] \mathrm{NE}$ was well confined to the ipsilateral side and was not detectable in ventricular spaces. The radius of diffusion was $<1.0 \mathrm{~mm}$ from the tip of the injector. As a consequence, data from experimental animals whose cannula tips lay beyond $1 \mathrm{~mm}$ of the $\mathrm{PVH}$, or invaded either the $\mathrm{PVH}$ itself or the third ventricle, were not included in the analysis. Using the nomenclature of Swanson and Kuypers (1980), placements varied from the level of the anterior parvocellular part of the PVH (referred to here as rostral injections) to that of the maximum development of the posterior magnocellular part of the nucleus (mid-PVH injections). Representative injection sites are shown in Figure $1 C$.

\section{Plasma corticosterone}

To examine the effects of neurotransmitter microinjection on secretory activity of the HPA axis, plasma corticosterone levels were monitored in a separate group of rats. In response to microinjection of saline, hormone titers displayed a relatively mild, but significant $(p<0.05)$, increase from resting levels of $37 \pm 26 \mathrm{ng} / \mathrm{ml}$ in rats to $170 \pm 77 \mathrm{ng} / \mathrm{ml}$ at $30 \mathrm{~min}$ after injection (Fig. 2), presumably attributable to the effects of handling and/or repeated blood sampling. Unilateral injection of $\mathrm{NE}(25 \mathrm{nmol})$ or the $\mathrm{GABA}_{\mathrm{A}}$ receptor antagonist BMI $(100 \mathrm{pmol})$ provoked corticosterone secretory responses that were comparable $(387 \pm 171$ and $362 \pm 42 \mathrm{ng} / \mathrm{ml}$, respectively) and significantly greater than those seen in response to saline at the $30 \mathrm{~min}$ peak time point $(p<0.05)$. In contrast, Glu $(1 \mathrm{nmol})$ did not produce a significant elevation in plasma corticosterone above control levels at $30 \mathrm{~min}$ $(236 \pm 86 \mathrm{ng} / \mathrm{ml})$ or any other postinjection time point $(p>$ $0.05)$. 

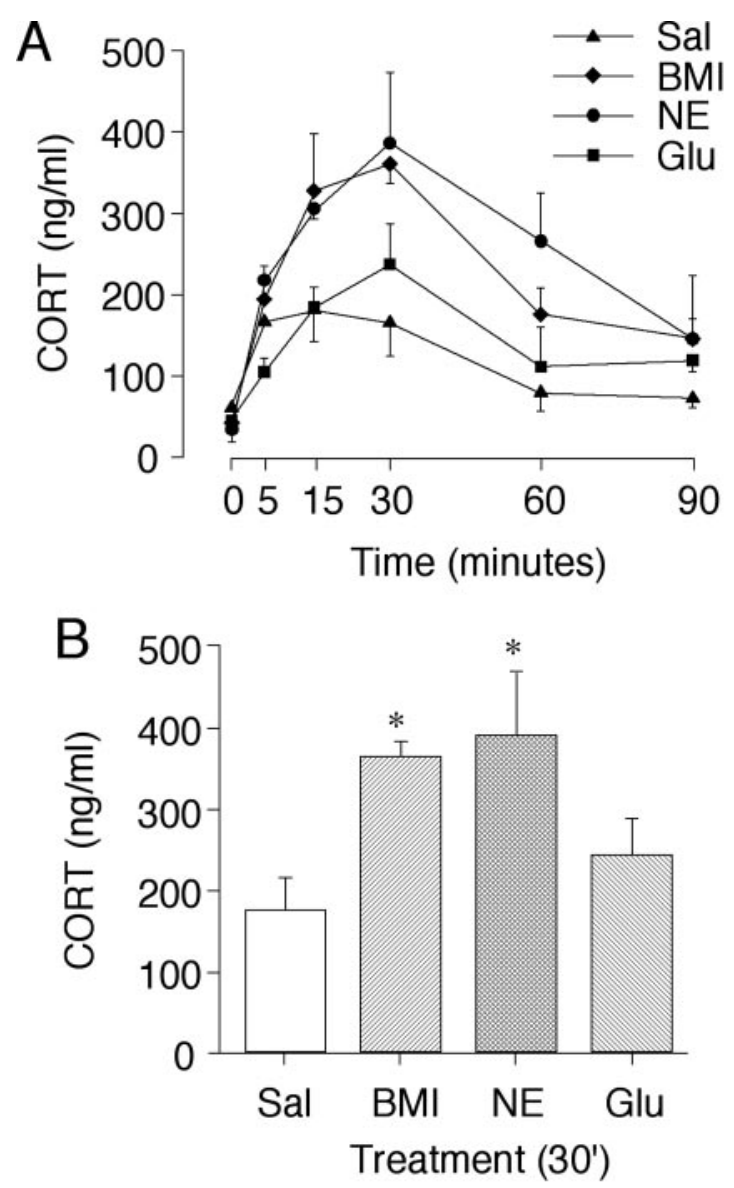

Figure 2. Plasma corticosterone levels are significantly increased above control levels by microinjections of norepinephrine or bicuculline, but not glutamate, into the PVH. $A$, Mean \pm SEM plasma corticosterone $(C O R T)$ concentrations at various time points after PVH microinjection of saline (Sal), $25 \mathrm{nmol}$ of NE, 100 pmol of BMI, or $1 \mathrm{nmol}$ of Glu. $n=$ 4 per group. $B$, Compared with saline-injected controls, a significant elevation in peak plasma corticosterone is observed at $30 \mathrm{~min}$ after NE or BMI injection ( $p<0.05$ by one-way ANOVA). Plasma corticosterone was not significantly increased after Glu microinjection.

\section{Fos induction}

Animals killed $2 \mathrm{hr}$ after saline microinjection displayed little Fos-IR within the PVH, proper (Fig. 3, Table 1). The scattered Fos-immunoreactive neurons seen in immediately adjoining regions were similar in density and distribution to that described previously in nonmanipulated rats (Chan et al., 1993). Microinjection of $25 \mathrm{nmol}$ of NE provoked a robust induction of Fos-IR that was strongly focused in the PVH and manifest across all its functional compartments (Fig. 3, Table 1). This occurred in the absence of any overt behavioral response to drug treatment. Responsive subregions included aspects of the medial parvocellular part of the nucleus in which hypophysiotropic CRF-expressing neurons are concentrated, components of the magnocellular division that harbor both oxytocin- and vasopressin-producing cells, and each of the subdivisions (ventral medial, dorsal, and lateral parvocellular) that give rise to autonomic-related projections to the brainstem and spinal cord. The intensity of Fos-immunoreactive labeling tended consistently to be greater in magnocellular than parvocellular regions. When injection sites were localized at the level of the mid-PVH, this pervasive pattern of $\mathrm{PVH}$ activation displayed a strong ipsilateral predominance, with no responsiveness noted in the supraoptic nucleus, another major seat of magnocellular neurosecretory neurons. In contrast, animals that received more rostrally placed NE injections manifest a similar pattern of Fos induction in the PVH, but that was bilaterally symmetrical and prominently included the supraoptic nucleus, again on both sides of the brain (Fig. 4). Bilateral activation of the PVH after rostrally placed microinjections is unlikely to be attributable to the diffusion of drug based on results obtained with $\left[{ }^{3} \mathrm{H}\right] \mathrm{NE}$ (Fig. 1). Alternatively, it is possible that the bilateral activation may be a secondary response to some physiological consequence of NE microinjection. Our data argue against this, because brainstem cell groups such as the nucleus of the solitary tract and/or ventrolateral medulla that would likely mediate such an effect were not observed to be responsive in these animals (data not shown). Finally, the bilateral hypothalamic response pattern might result from the involvement of a cell group situated in proximity to rostrally placed injections that is known to both receive a noradrenergic input and to project bilaterally to the $\mathrm{PVH}$ and supraoptic nucleus. The median preoptic nucleus meets these criteria and its involvement provides a viable explanation for the bilateral activation pattern, because rats that received rostrally placed PVH injections consistently exhibited Fos induction in this cell group, whereas those whose cannulas were centered at the level of the mid-PVH did not (Fig. 4).

Microinjection of the $\mathrm{GABA}_{\mathrm{A}}$ receptor antagonist BMI typically provoked intense behavioral activation (increased locomotion, jumping, running, and grooming). In contrast to the focal pattern of cellular activation seen in response to NE treatment, microinjections of BMI produced a massive Fos induction centered about the tip of the injection cannula that ostensibly did not respect nuclear boundaries. That is, comparably robust responses were seen in nearly all proximal cell groups of the ventral thalamus and dorsomedial hypothalamus, including the parvocellular division of the PVH (Fig. 3, Table 1). In contrast, however, relatively few weakly labeled Fos-positive neurons were observed in the magnocellular division of the nucleus in most, but not all, animals. This basic pattern was highly lateralized and obtained regardless of the rostrocaudal level of the cannula placement. This result suggests that, in the nonstressed animal, parvocellular and magnocellular neurosecretory neurons rest under differential GABAergic control.

In line with the results of corticosterone assays, microinjection of Glu (1 nmol) provoked only a weak induction of Fos-IR in the PVH. Typically, these injections gave rise to a relatively small number of weakly labeled nuclei concentrated mainly in autonomic-related aspects of the PVH, including the dorsal, ventral medial, and lateral parts of the parvocellular division of the nucleus on the side ipsilateral to the injection (Fig. 5, Table 1). In these preparations, we observed only a modest activational response in the CRF-rich hypophysiotropic zone of the PVH and little or no apparent Fos induction in the magnocellular division of the nucleus. Comparably muted responses were seen in the PVH after doses of Glu ranging from 0.1 to $100 \mathrm{nmol}$ (data not shown). In control experiments, injections of $1 \mathrm{nmol}$ of Glu into the hippocampal formation gave rise to robust activational responses (Fig. 5).

One possible explanation for the surprisingly muted response to glutamate microinjection could involve concurrent activation of GABA-mediated local inhibitory mechanisms known to reside in the perinuclear zone immediately surrounding the PVH (Roland and Sawchenko, 1993; Boudaba et al., 1996). To test the viability of this hypothesis, immunolabeling for Glu-induced Fos-IR was combined with hybridization histochemical detection of GAD-67 

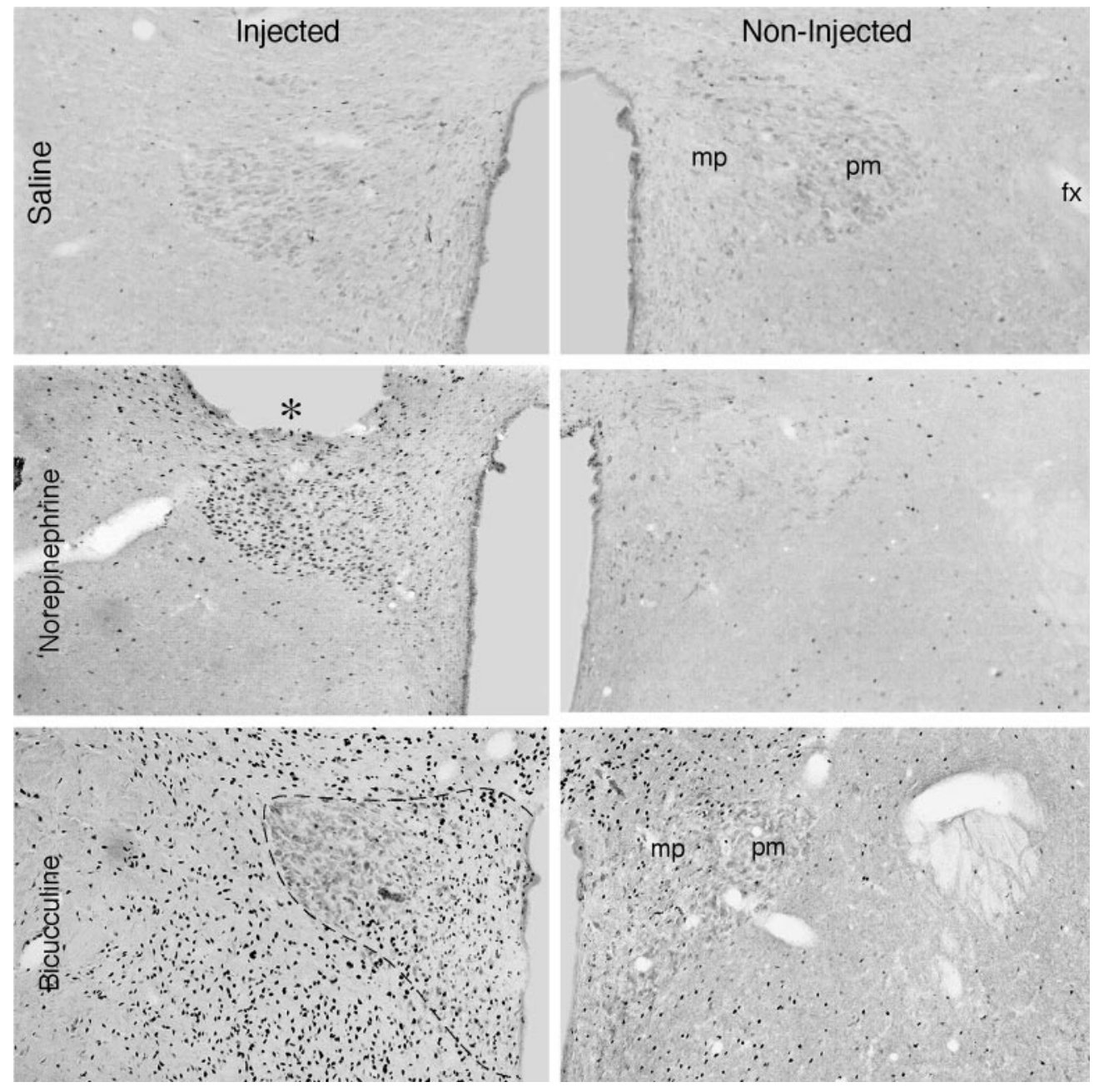

Figure 3. Distinct patterns of cellular activation evoked by microinjection of bicuculline or norepinephrine. Brightfield photomicrographs of sections through the PVH on the sides ipsilateral (injected; left) and contralateral (noninjected; right) to microinjections of saline (top), $25 \mathrm{nmol}$ of NE (middle), or 100 pmol of BMI (bottom) at the level of the mid-PVH. Saline-treated animals displayed very low-level Fos expression whose pattern and strength was indistinguishable from that seen in nonmanipulated rats. NE provoked a robust and lateralized Fos induction, highly focussed in the $\mathrm{PVH}$, that encompassed all major functional compartments of the magnocellular and parvocellular divisions of the nucleus. BMI, in contrast, gave rise to Fos induction with the $\mathrm{PVH}$ that was highly confined to the parvocellular division of the nucleus and equally prominent in immediately adjoining areas, outside the $\mathrm{PVH}$, proper. Magnification: $60 \times . m p$, Medial parvocellular part $(\mathrm{PVH}) ; p m$, posterior magnocellular part (PVH); $f x$, fornix. Asterisk indicates injection site.

Table 1. Drug-induced Fos induction in select PVH compartments ${ }^{a}$

$\underline{\text { Parvocellular neurosecretory }^{b}}$

Autonomic

Magnocellular neurosecretory

\begin{tabular}{lccccc} 
Treatment $(n)$ & $\mathrm{pv}$ & $\mathrm{mp}$ & $\mathrm{dp}$ & $\mathrm{lp}$ & $\mathrm{pm}$ \\
\hline Saline (6) & $16 \pm 4^{c}$ & $28 \pm 6$ & $8 \pm 2$ & $8 \pm 5$ & $5 \pm 4$ \\
Norepinephrine (5) & $144 \pm 22$ & $590 \pm 70$ & $121 \pm 15$ & $134 \pm 12$ & $580 \pm 45$ \\
Bicuculline (6) & $191 \pm 33$ & $682 \pm 85$ & $136 \pm 19$ & $186 \pm 17$ & $72 \pm 16$ \\
Glutamate (6) & $28 \pm 3$ & $112 \pm 9$ & $44 \pm 5$ & $52 \pm 8$ & $16 \pm 2$
\end{tabular}

${ }^{a}$ Parcellation is based on Swanson and Kuypers (1980). pv, Periventricular part; mp, medial parvocellular part; dp, dorsal parvocellular part; lp, lateral parvocellular part; pm, posterior magnocellular part.

${ }^{b}$ Major headings indicate the dominant visceromotor cell type(s) contained in each subdivision. Note that the medial parvocellular part contains substantial complements of both parvocellular neurosecretory and autonomic-related neurons. ${ }^{c}$ Values given are mean $\pm \mathrm{SEM}$.

mRNA, a marker for GABAergic neurons. In material from control (saline-injected) animals, a substantial proportion of the relatively small number of scattered neurons in regions immediately adjoining the PVH that exhibited Fos-IR under nonstimulated conditions displayed positive hybridization signals for GAD-67 mRNA (Fig. 6). Regions displaying such double-labeled cells included the anterior and perifornical hypothalamic areas, the posteromedial part of the bed nucleus of the stria terminalis, the rostromedial zona incerta, and the areas immediately laterally and ventrally subjacent to the PVH. Animals receiving appropriately placed injections of Glu displayed an apparent increase in the number of Fos-immunoreactive neurons in the aforementioned areas that lay within the presumed effective injection site, with clear elevations evident in the anterior hypothalamic area and the perinuclear region of the PVH. Once again, the great majority of Fos-immunoreactive neurons in material from Glu-injected rats 
Figure 4. Rostrally placed norepinephrine injections give rise to bilateral activation of both the PVH and the supraoptic nucleus. Brightfield photomicrographs of sections through the $\mathrm{PVH}$ (top) and the supraoptic nucleus (middle) on the sides ipsilateral (injected; left) and contralateral (noninjected; right) to a microinjection of $25 \mathrm{nmol}$ of NE centered at the level of the rostral PVH. In contrast to the highly lateralized effects seen after mid-PVH injections (see Fig. 3), more rostrally placed injections gave rise to a bilateral pattern of activation in the $\mathrm{PVH}$, which included the supraoptic nucleus, also bilaterally. This distinctive pattern of activation could be attributable to concurrent involvement of a cell group that lay within the sphere of the injection site, exhibits NE sensitivity, and projects bilaterally to both the $\mathrm{PVH}$ and supraoptic nucleus. These attributes are displayed by the median preoptic nucleus (bottom), which exhibited robust Fos induction in response to $\mathrm{NE}$ administration at rostral, but not mid-PVH, levels. Magnification: $60 \times$. $a c$, Anterior commissure; $M e P O$, median preoptic nucleus; $S O$, supraoptic nucleus.
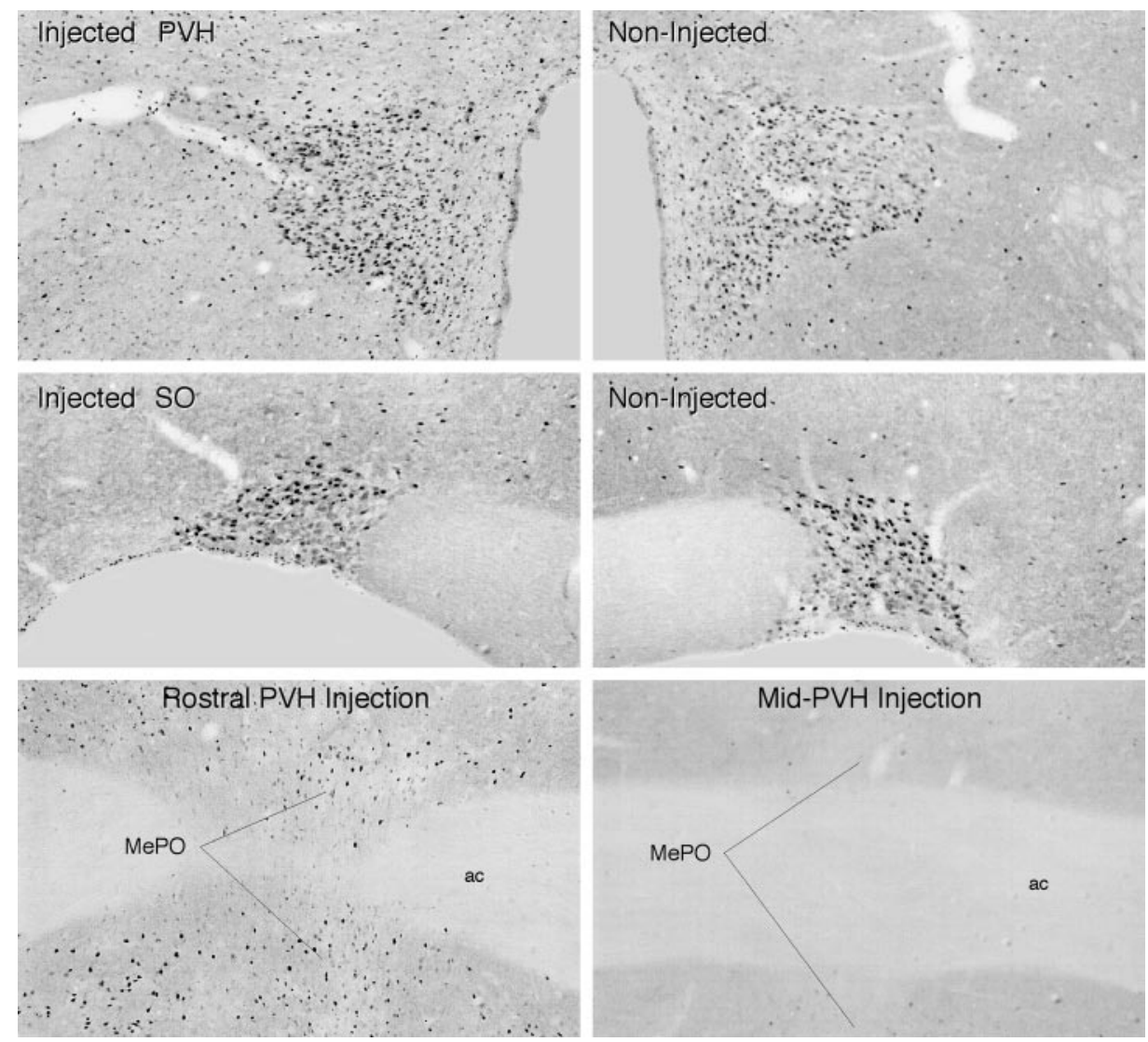

Figure 5. Local glutamate injection produces a modest activational response in the PVH. Top, Bright-field photomicrographs showing Fos-IR expression in and around the PVH on the side ipsilateral (injected; left) and contralateral (noninjected; right) to a microinjection of $1 \mathrm{nmol}$ of Glu. Only a modest activational response, localized principally to the autonomic-related dorsal and ventral medial parts of the parvocellular division of the nucleus, was observed. Note also the substantial induction of Fos-IR in regions immediately adjoining the PVH. Bottom, In contrast to the PVH, microinjection of $1 \mathrm{nmol}$ of Glu into the hippocampal formation produces a marked increase in Fos-IR on the injected side of the brain, particularly in the granule cell layer of the dentate gyrus. Asterisk marks tip of injection cannula. Magnification: $60 \times . m p$, Medial parvocellular part (PVH); $\mathrm{pm}$, posterior magnocellular part (PVH); $f x$, fornix.
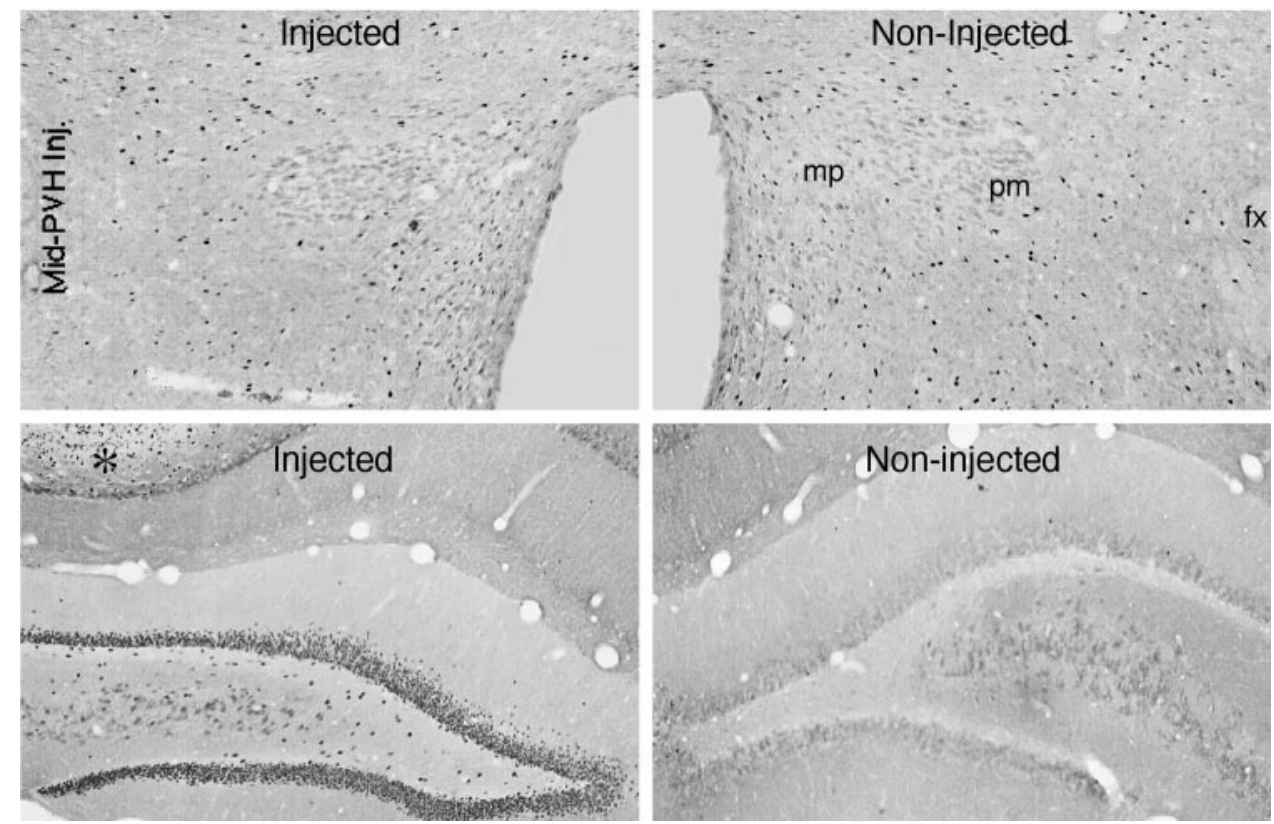

displayed positive hybridization signals for GAD-67 message (Fig. 6). Counts of the average number of double-labeled cells in one representative region, the central part of the anterior hypothalamic area, revealed a mean of $36.0 \pm 6.4$ cells per section in Glu-injected animals $(n=8)$ compared with $13.4 \pm 1.1$ cells per section in saline-treated controls $(n=4)$; these represented 74 and $79 \%$, respectively, of all Fos-positive cells counted in this cell group under these conditions. Overall, these data indicate that at least some local GABAergic interneurons exhibit Glu sensitivity, although it remains to be determined to what extent these may contribute afferent projections to the PVH.

\section{Transcriptional activation of the neuropeptide genes in the parvocellular division of the PVH}

Previous work (Kovács and Sawchenko, 1996) has described temporally distinct patterns of stress-induced transcriptional activa- 


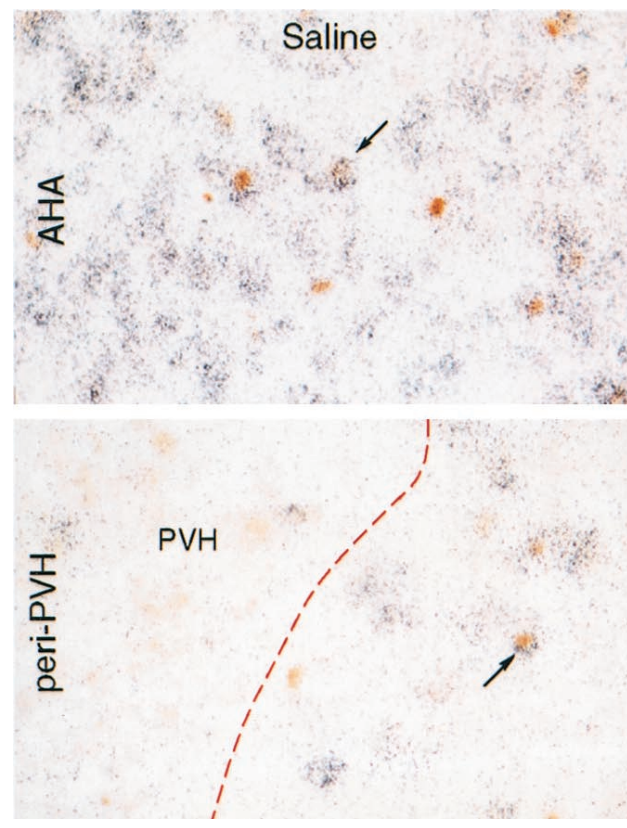

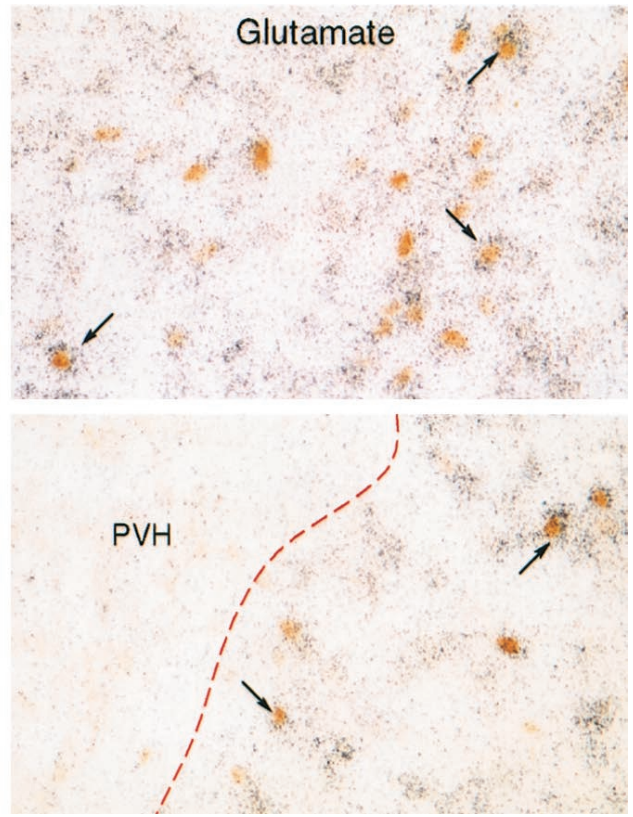

Figure 6. Glutamate microinjection activates perinuclear GABAergic neurons. Bright-field photomicrographs showing Fos-IR expression (brown nuclear product) combined with hybridization histochemical localization of GAD-67 mRNA (black cytoplasmic grains) in the anterior hypothalamic area $(A H A ;$ top $)$ and perinuclear zone of the PVH ( peri-PVH; bottom) of control (salineinjected; left) and glutamate-injected (right) rats. Under control conditions, a majority of the relatively small number of cells displaying Fos-IR are colabeled for GAD-67 mRNA. Local glutamate administration substantially increases the number of Fosimmunoreactive neurons in these regions (but not in the PVH itself); most of the glutamate-sensitive perinuclear neurons also display the marker for the GABAergic phenotype. Arrows denote examples of doublelabeled cells. Magnification: $230 \times$.
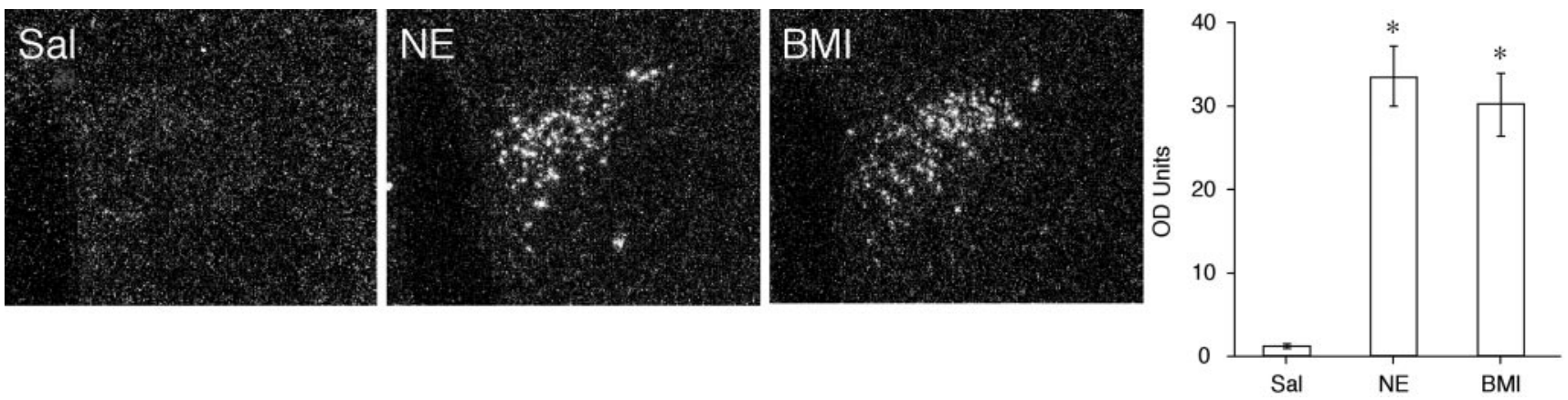

Figure 7. Both NE and BMI microinjection induce CRF gene transcription in the parvocellular division of the PVH. Left, Dark-field photomicrographs depicting CRF hnRNA expression in the parvocellular division of the PVH after microinjection of saline (Sal), 100 pmol of BMI, and $25 \mathrm{nmol}$ of NE. Animals were killed 20 min after microinjection. Both NE and BMI microinjection produce a robust increase in hnRNA encoding for CRH peptide in the parvocellular division of the PVH. Magnification: $45 \times$. Right, Mean \pm SEM relative levels of CRF hnRNA in the parvocellular PVH of rats killed 20 min after saline, NE, or BMI injection. $n=4-6$ per group. ${ }^{*} p<0.05$ by one-way ANOVA.

tion of the genes encoding the two principal corticotropin secretagogues expressed by parvocellular neurosecretory neurons, with significant elevations of CRF hnRNA seen at early (5-30 min) post-stress time points and AVP intronic responses substantially later (60-120 min). To determine the extent to which NE and GABA mechanisms may mimic, and potentially participate in, this differential control, material from rats killed 20 or $90 \mathrm{~min}$ after microinjection of $\mathrm{NE}$ or BMI was analyzed for relative levels of primary CRF and AVP transcripts.

Animals receiving microinjection of saline displayed very low levels of CRF hnRNA expression in the parvocellular division of the $\mathrm{PVH}$, whose relative strength and distribution was similar to that described in untreated rats. Relative to these control animals, rats killed at $20 \mathrm{~min}$ after either NE or BMI microinjection displayed comparable (30.6-fold and 27.5-fold), and statistically reliable ( $p$ values $<0.05$ ), increases in relative levels of CRF hnRNA in the parvocellular division of the PVH (Fig. 7). Thus, in vivo, both adrenergic receptor activation and $\mathrm{GABA}_{\mathrm{A}}$ receptor blockade can stimulate CRF gene expression.

In contrast to the low basal level of CRF hnRNA expression, primary AVP transcripts were readily detectable in saline- injected control rats killed at 90 min after injection, concentrated principally in the magnocellular division of the nucleus, with a relatively small number of cells of similar size and labeling intensity scattered throughout the parvocellular region (Fig. 8). No clear evidence suggestive of AVP hnRNA expression by smaller neurons in the hypophysiotropic zone of the medial parvocellular part of the nucleus was evident under this control condition. In contrast, rats killed at the same time point after BMI, but not NE, microinjection displayed a reliable 2.7-fold increase in relative levels of AVP hnRNA in the parvocellular division of the $\mathrm{PVH}$, as assessed by population densitometry $(p<0.05)$ (Fig. 8).

Although NE treatment failed to provoke a significant increase in AVP intronic expression, the appearance of the material suggested that small cells within the parvocellular division were manifesting induced AVP expression. Because the presence of scattered magnocellular neurons that express AVP at high basal levels is known to be capable of interfering with detection of relatively subtle changes in AVP expression in the parvocellular division of the $\mathrm{PVH}$, cell counts were undertaken to assay for the presence of a reliable AVP response. This analysis revealed a 

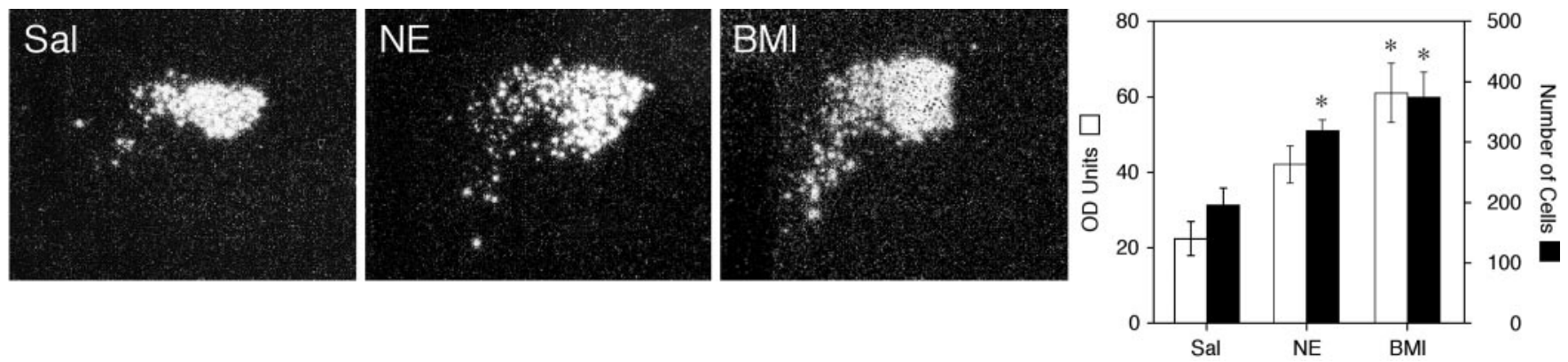

Figure 8. AVP gene transcription in the parvocellular division of the PVH in response to microinjection of BMI or NE. Left, Dark-field photomicrographs showing AVP hnRNA expression in the parvocellular division of the PVH after microinjection of saline (Sal), 100 pmol of BMI, and $25 \mathrm{nmol}$ of NE. Animals were killed $90 \mathrm{~min}$ after microinjection. Whereas robust expression of the primary AV P transcripts in the magnocellular division of the PVH is evident under each condition, AVP hnRNA expression in the parvocellular PVH is induced in response to BMI injection, with a substantially more muted response seen after NE administration. Magnification: $45 \times$. Right, Mean \pm SEM relative levels of AVP hnRNA after PVH microinjection of saline, NE, and BMI, as assessed by population densitometry (open bars) and cell counts ( filled bars). $n=4-6$ per group. ${ }^{*} p<0.05$ by one-way ANOVA. Only the BMI effect on AVP hnRNA was significant based on densitometric analysis, although both drugs elicited reliable increases in the number of neurons exhibiting positive hybridization signal in the parvocellular division of the PVH.

significant increase in the number of neurons in the parvocellular region that manifested AVP hnRNA expression in response to $\mathrm{NE}$ microinjection $(p<0.05)$. The magnitude of this increment $(42 \%)$ was somewhat less than that seen in response to BMI injection (79\%) (Fig. 8), although the values did not differ significantly from one another. Thus, our findings support the view that both NE and BMI have the capacity to increase AVP hnRNA in the parvocellular division of the $\mathrm{PVH}$, with the $\mathrm{GABA}_{\mathrm{A}}$ receptor antagonist manifesting greater efficacy under the conditions in force in these experiments.

\section{DISCUSSION}

Microinjection studies examined the effects of manipulating three major neurotransmitter systems on various indices of PVH effector neuron activity, focusing on parvocellular neurosecretory neurons that comprise the central limb of the HPA axis. Corticosterone secretion, Fos induction, and neuropeptide gene transcription were all activated by local adrenergic receptor stimulation or $\mathrm{GABA}_{\mathrm{A}}$ receptor blockade but not by glutamate. Response profiles elicited by NE and BMI differed with respect to the complement of $\mathrm{PVH}$ effector populations that were recruited and the extent to which AVP transcriptional activation in hypophysiotropic neurons was provoked. The results support differential involvement of adrenergic, GABAergic, and glutamatergic mechanisms in governing PVH outputs. However, ancillary observations suggest that involvement of local circuit neurons may complicate the interpretation of such microinjection studies.

\section{Norepinephrine microinjection produces robust PVH activation}

Unilateral norepinephrine microinjection produced a significant increase in plasma corticosterone levels, in accord with many previous studies documenting elevations in plasma ACTH and corticosterone titers after central NE administration (Szafarczyk et al., 1987; Leibowitz et al., 1989). These effects are likely mediated principally by $\alpha 1$ adrenergic receptors located on CRFexpressing PVH neurons (Plotsky et al., 1987). In line with this, $\mathrm{NE}$ injection provoked Fos induction in the hypophysiotropic zone of the PVH and, in addition, robust activation of magnocellular neurosecretory and autonomic-related populations within the PVH. This is consistent with the broad distribution of adrenoceptor binding and expression data, with some subtypes appearing to be localized preferentially to the magnocellular $(\alpha 2 \mathrm{~A}$ :
Nicholas et al., 1993; $\alpha 2$ C: Rosin et al., 1996) or parvocellular divisions of the nucleus ( $\alpha 1 \beta$ : Day et al., 1999) and others more broadly ( $\alpha 1 \mathrm{D}$ : Sands and Morilak, 1999). It is of interest to note that a comparably broad pattern of cellular activation is seen in the PVH in response to hypotensive hemorrhage (Badoer et al., 1992; Chan et al., 1993), and recent data support a primary involvement of ascending catecholaminergic projections in mediating PVH responses to this challenge (Chan et al., 2001).

This broad pattern of NE-induced cellular activation was primarily confined to the ipsilateral (injected) side when NE was administered at the level of the mid-PVH but was bilaterally symmetrical, with strong involvement of the supraoptic nucleus, when injections were placed more rostrally. The bilateral response may result from activation of more rostrally situated structures, such as the median preoptic nucleus, which is known to receive noradrenergic input (Saper and Levisohn, 1983) and to project bilaterally to the PVH and supraoptic nucleus (Sawchenko and Swanson, 1983).

In support of previous observations (Itoi et al., 1999), our experiments also demonstrate that $\mathrm{NE}$ gives rise to a rapid and reliable increase in CRF hnRNA in the parvocellular division of the PVH. In contrast to the results of Itoi et al. (1999), however, our findings also support a responsiveness of parvocellular AVP gene expression to this manipulation. This increase was not readily detectable by densitometric analysis but was revealed by cell counts. One possible explanation for this discrepancy is the exposure time used for autoradiograms. We used a longer (3 week) interval to optimize detection of relatively low level AVP hnRNA expression in the parvocellular division of the $\mathrm{PVH}$, whereas Itoi et al. (1999) used a shorter exposure time (1 week) to enable concurrent analysis of the substantially higher level of expression in magnocellular neurosecretory neurons. It is possible that the shorter exposure time was not adequate to fully reveal the expression of AVP hnRNA in the parvocellular division of the PVH. In any event, our results support a capacity of local NE administration to initiate AVP transcription in parvocellular neurons, although the response was observed to be relatively weak under the experimental conditions we used.

\section{Effects of GABA antagonism on PVH activity}

Many previous studies have shown potent activational effects of BMI injections into the PVH. These include robust increases in 
autonomic parameters, such as blood pressure and heart rate (Martin et al., 1991; Martin and Haywood, 1993). The cellular populations in the $\mathrm{PVH}$ that are responsive to BMI microinjection have not yet been defined. Here we show that, despite their similar effects on plasma corticosterone levels, BMI and NE produced distinctive patterns of cellular activation within the PVH. BMI strongly and preferentially activated neurons in the parvocellular neurosecretory and autonomic subregions of the nucleus, although its effects were muted or lacking in the magnocellular compartment. This result is consistent with a study supporting predominantly parvocellular targets of perinuclear GABAergic neurons (Roland and Sawchenko, 1993) and suggests that parvocellular and magnocellular neurosecretory neurons are under differential GABAergic control. Interestingly, electrophysiological evidence indicates that magnocellular and parvocellular elements of the $\mathrm{PVH}$ are under similar inhibitory, $\mathrm{GABA}_{\mathrm{A}}$ receptor-mediated control by local interneurons (Tasker and Dudek, 1993). The basis for the apparent lack of congruence of the electrophysiological and anatomical data are unclear.

It should be noted that, although NE-induced activational responses were preferentially localized to the $\mathrm{PVH}$, those provoked by BMI did not respect nuclear borders (Fig. 3) and may well have included local GABAergic interneurons (see below), but this was not examined directly.

BMI produced robust increases in both CRF and AVP hnRNA expression within the parvocellular PVH. This supports an involvement of GABAergic mechanisms in regulating the expression of both major corticotropin secretagogues in hypophysiotropic neurons. The fact that BMI elicited more robust AVP transcriptional activation than NE, while similarly affecting corticosterone secretion and CRF hnRNA expression, may be indicative of a preferential involvement of GABAergic mechanisms in regulating AVP dynamics in this cell type. It has been noted that perinuclear GABAergic neurons that provide input to the $\mathrm{PVH}$ are in position to mediate well documented, and generally inhibitory, influences of limbic system structures on resident neurosecretory neuron pools (Roland and Sawchenko, 1993; Boudaba et al., 1996). The limbic region, particularly the hippocampal formation, is enriched in corticosteroid receptor expression and has been strongly implicated in mediating glucocorticoid negative feedback effects on the HPA axis. Coupled with recent indications that steroid feedback effects are exerted selectively on AVP expression (Kovács et al., 2000), the present findings would seem to warrant additional consideration of the involvement of local GABAergic mechanisms in the feedback control of AVP expression (Acs et al., 1985).

Previous studies have shown that low doses (10 pmol) of BMI microinjected into the dorsomedial nucleus of the hypothalamus, which lies immediately caudal to the $\mathrm{PVH}$, can have potent affects on PVH activity (De Novellis et al., 1995; DiMicco et al., 1996). Although the sphere of drug distribution observed in our experiments with $\left[{ }^{3} \mathrm{H}\right] \mathrm{NE}$ (Fig. 1) does not necessarily generalize to that of BMI, the lack of detectable Fos-IR in the dorsomedial nucleus of BMI-injected rats makes it seem unlikely that the effects we observed are a result of a primary site of action other than in the PVH.

\section{The effect of glutamate microinjection on PVH activity}

Glutamate microinjection elicited surprisingly weak effects on plasma corticosterone levels and Fos expression within the PVH. This result was unexpected, because the PVH is known to express a variety of (mainly ionotropic) glutamate receptors (van den Pol et al., 1994; Aubry et al., 1996; Herman et al., 2000; Eyigor et al., 2001) and to receive a substantial glutamatergic innervation (van den Pol et al., 1990; van den pol, 1991). The role of glutamate in the regulation of PVH mechanisms is unsettled, and its effects on parvocellular neurosecretory neurons have not been thoroughly characterized (Oliver et al., 1996; Herman and Cullinan, 1997). For example, in vitro studies report that hypothalamic CRF release may be increased (Joanny et al., 1997) decreased, or unaffected (Costa et al., 1992; Patchev et al., 1994) by excitatory amino acid administration. Another reports that glutamate alone has no effect on hypothalamic cultures but can potentiate the effects of forskolin (Yang et al., 1995). Peripheral EAA administration results in increased ACTH and corticosterone levels (Jezova et al., 1991), but the site of action for this effect is undetermined (Oliver et al., 1996). Similarly conflicting results have been reported on the effects of local glutamate injection on autonomic (cardiovascular) parameters (Katafuchi et al., 1988; Darlington et al., 1989; Martin and Haywood, 1992; DiMicco et al., 1996). Several studies have reported that microinjection of glutamate directly into the $\mathrm{PVH}$ results in increased plasma ACTH and corticosterone (Darlington et al., 1989; Feldman and Weidenfeld, 1997). The basis for the apparent conflict between these and the present results is not entirely clear, although these previous studies were performed acutely in pentobarbital anesthetized rats, whereas ours were in awake behaving animals with implanted cannulas. Potentially, gliosis around chronically implanted cannulas could act as a sink to take up injected glutamate and dampen injection effects. This seems unlikely to account for the muted responses observed here, because our injections did produce a mild activation of the autonomic compartment of the PVH and a more pronounced response in select perinuclear areas. In addition, injections into the hippocampal formation using a similar approach provoked strong activational responses (Fig. 5).

Considerations of dosage may also be relevant to reconciling the disparate results concerning glutamatergic regulation of $\mathrm{PVH}$ mechanisms. It has been cautioned that, whereas microinjection of low doses $(<5 \mathrm{nmol})$ of glutamate can produce excitation, higher doses can result in long-lasting inhibition as a consequence of depolarization block (Lipski et al., 1988). In our studies, doses of glutamate ranging from 100 pmol to 100 nmol produced comparable effects, and the primary $(1 \mathrm{nmol})$ dose is within the range that would be expected to yield interpretable results.

Finally, the lack of glutamate effects may be attributable in part to concurrent stimulation of local inhibitory GABAergic neurons. We observed in control animals that a significant proportion of perinuclear Fos-positive cells displayed a marker of the GABAergic phenotype and that the number of such double-labeled cells was increased in response to local glutamate application. In view of anatomical evidence to support the existence of inputs to the parvocellular PVH from perinuclear GABA cells (Roland and Sawchenko, 1993) and electrophysiological work to indicate that such inhibitory interneurons are sensitive to glutamate (Tasker and Dudek, 1993; Boudaba et al., 1996), it is possible that activation of local circuit neurons by excitatory amino acids may serve to dampen direct neurotransmitter effects on populations intrinsic to the PVH. It remains to be determined to what extent local glutamate-sensitive GABAergic elements identified in our experiments actually contribute to the innervation of the PVH in general and to that of parvocellular neurosecretory neurons in particular. Current understanding of the distribution of glutamate receptors in and around the $\mathrm{PVH}$ is of limited value in ascertain- 
ing a likely site of action, because some are localized preferentially to the $\mathrm{PVH}$, some to perinuclear regions, and still others distributed ubiquitously across both (Herman et al., 2000; Eyigor et al., 2001). In any event, the present findings call attention to the potential confounding influence of local circuit neurons in interpreting the effects of microinjection studies, which, in this instance, leave open to question the nature and any selectivity of glutamatergic regulation of PVH effector populations.

\section{REFERENCES}

Abercrombie M (1946) Estimation of nuclear population from microtome sections. Anat Rec 94:239-247.

Acs Z, Lutz-Bucher B, Koch B, Stark B (1985) Vasopressin secretion as a possible target of $\gamma$-aminobutyric acid-mediated component of the corticosteroid feedback effect. J Endocrinol 107:303-307.

Antoni FA (1993) Vasopressinergic control of pituitary adrenocorticotropin secretion comes of age. Front Neuroendocrinol 14:76-122.

Aubry JM, Bartanusz V, Pagliusi S, Schulz P, Kiss JZ (1996) Expression of ionotropic glutamate receptor subunit mRNAs by paraventricular corticotropin-releasing factor (CRF) neurons. Neurosci Lett 205:95-98.

Badoer E, McKinley MJ, Oldfield BJ, McAllen RM (1992) Distribution of hypothalamic, medullary and lamina terminalis neurons expressing Fos after hemorrhage in conscious rats. Brain Res 582:323-328.

Boudaba C, Szabo K, Tasker JG (1996) Physiological mapping of local inhibitory inputs to the hypothalamic paraventricular nucleus. J Neurosci 16:7151-7160.

Brann DW (1995) Glutamate: a major excitatory transmitter in neuroendocrine regulation. Neuroendocrinology 61:213-225.

Ceccatelli S, Villar MJ, Goldstein M, Hökfelt T (1989) Expression of c-Fos immunoreactivity in transmitter-characterized neurons after stress. Proc Natl Acad Sci USA 86:9569-9573.

Chan JY, Yang SM, Chan SH (1998) Mediation by $N$-methyl-Daspartate and non- $N$-methyl-D-aspartate receptors in the expression of Fos protein at the nucleus tractus solitarii in response to baroreceptor activation in the rat. Neuroscience 83:93-105.

Chan RK, Brown ER, Ericsson A, Kovács KJ, Sawchenko PE (1993) A comparison of two immediate-early genes, c-fos and NGFI-B, as markers for functional activation in stress-related neuroendocrine circuitry. J Neurosci 13:5126-5138.

Chan RKW, Rissman RA, Sawchenko PE (2001) Hypotensive challenge effects on hypothalamic neuropeptide gene expression and their afferent mediation. J Comp Neurol, in press.

Cole RL, Sawchenko PE (1998) Differential effects of norepinephrine and glutamate microinjection on activation of the paraventricular nucleus. Soc Neurosci Abstr 24:118.

Costa A, Yasin SA, Hucks D, Forsling ML, Besser GM, Grossman A (1992) Differential effects of neuroexcitatory amino acids on corticotropin-releasing hormone-41 and vasopressin release from rat hypothalamic explants. Endocrinology 131:2595-2602.

Cunningham Jr ET, Sawchenko PE (1988) Anatomical specificity of noradrenergic inputs to the paraventricular and supraoptic nuclei of the rat hypothalamus. J Comp Neurol 274:60-76.

Darlington DN, Miyamoto M, Keil LC, Dallman MF (1989) Paraventricular stimulation with glutamate elicits bradycardia and pituitary responses. Am J Physiol 256:R112-R119.

Day HE, Campeau S, Watson Jr SJ, Akil H (1999) Expression of alpha $(1 \beta)$ adrenoceptor mRNA in corticotropin-releasing hormonecontaining cells of the rat hypothalamus and its regulation by corticosterone. J Neurosci 19:10098-10106.

De Novellis V, Stotz-Potter EH, Morin SM, Rossi F, DiMicco JA (1995) Hypothalamic sites mediating cardiovascular effects of microinjected bicuculline and EAAs in rats. Am J Physiol 269:R131-R140.

Decavel C, van den Pol AN (1990) GABA: a dominant neurotransmitter in the hypothalamus. J Comp Neurol 302:1019-1037.

DiMicco JA, Stotz-Potter EH, Monroe AJ, Morin SM (1996) Role of the dorsomedial hypothalamus in the cardiovascular response to stress. Clin Exp Pharmacol Physiol 23:171-176.

Ericsson A, Kovács KJ, Sawchenko PE (1994) A functional anatomical analysis of central pathways subserving the effects of interleukin-1 on stress-related neuroendocrine neurons. J Neurosci 14:897-913.

Eyigor O, Centers A, Jennes L (2001) Distribution of ionotropic glutamate receptor subunit mRNAs in the rat hypothalamus. J Comp Neurol 434:101-124.

Feldman S, Weidenfeld J (1997) Hypothalamic mechanisms mediating glutamate effects on the hypothalamo-pituitary-adrenocortical axis. J Neural Transm 104:633-642.

Gillies GE, Linton EA, Lowry PJ (1982) Corticotropin releasing activity of the new CRF is potentiated several times by vasopressin. Nature 299:355-357.

Hauger RL, Aguilera G (1993) Regulation of pituitary corticotropin releasing hormone $(\mathrm{CRH})$ receptors by $\mathrm{CRH}$ : interaction with vasopressin. Endocrinology 133:1708-1714.

Herman JP, Cullinan WE (1997) Neurocircuitry of stress: central control of the hypothalamo-pituitary-adrenocortical axis. Trends Neurosci 20:78-84.

Herman JP, Schafer MK-H, Watson SJ, Sherman TG (1991) In situ hybridization analysis of arginine vasopressin gene transcription using intron-specific probes. Mol Endocrinol 5:1447-1456.

Herman JP, Schafer MK-H, Thompson RC, Watson SJ (1992) Rapid regulation of corticotropin-releasing hormone gene transcription in vivo. Mol Endocrinol 6:1061-1069.

Herman JP, Eyigor O, Ziegler DR, Jennes L (2000) Expression of ionotropic glutamate receptor subunit mRNAs in the hypothalamic paraventricular nucleus of the rat. J Comp Neurol 422:352-362.

Huhman KL, Babagbemi TO, Albers HE (1995) Bicuculline blocks neuropeptide $\mathrm{Y}$-induced phase advances when microinjected in the suprachiasmatic nucleus of Syrian hamsters. Brain Res 675:333-336.

Imaki T, Xiao-Quan W, Shibasaki T, Yamada K, Harada S, Chikada N, Naruse M, Demura H (1995) Stress-induced activation of neuronal activity and corticotropin-releasing factor gene $\Omega$ expression in the paraventricular nucleus is modulated by glucocorticoids in rats. J Clin Invest 96:231-238.

Itoi K, Suda T, Tozawa F, Dobashi I, Ohmori N, Sakai Y, Abe K, Demura H (1994) Microinjection of norepinephrine into the paraventricular nucleus of the hypothalamus stimulates corticotropin-releasing factor gene expression in conscious rats. Endocrinology 135:2177-2182.

Itoi K, Helmreich DL, Lopez-Figueroa MO, Watson SJ (1999) Differential regulation of corticotropin-releasing hormone and vasopressin gene transcription in the hypothalamus by norepinephrine. J Neurosci 19:5464-5472.

Jezova D, Oliver C, Jurcovicova J (1991) Stimulation of adrenocorticotropin but not prolactin and catecholamine release by $N$-methylaspartic acid. Neuroendocrinology 54:488-492.

Joanny P, Steinberg J, Oliver C, Grino M (1997) Glutamate and $N$-methyl-D-aspartate stimulate rat hypothalamic corticotropinreleasing factor secretion in vitro. J Neuroendocrinol 9:93-97.

Katafuchi T, Oomura Y, Kurosawa M (1988) Effects of chemical stimulation of paraventricular nucleus on adrenal and renal nerve activity in rats. Neurosci Lett 86:195-200.

Kovács KJ, Sawchenko PE (1996) Sequence of stress-induced alterations in indices of synaptic and transcriptional activation in parvocellular neurosecretory neurons. J Neurosci 16:262-273.

Kovács KJ, Foldes A, Sawchenko PE (2000) Glucocorticoid negative feedback selectively targets vasopressin transcription in parvocellular neurosecretory neurons. J Neurosci 20:3843-3852.

Leibowitz SF (1978) Paraventricular nucleus: a primary site mediating adrenergic stimulation of feeding and drinking. Pharmacol Biochem Behav 8:163-175.

Leibowitz SF, Diaz S, Tempel D (1989) Norepinephrine in the paraventricular nucleus stimulates corticosterone release. Brain Res 496:219-227.

Lipski J, Bellingham MC, West MJ, Pilowsky P (1988) Limitations of the technique of pressure microinjection of excitatory amino acids for evoking responses from localized regions of the CNS. J Neurosci Methods 26:169-179.

Ma XM, Levy A, Lightman SL (1997) Rapid changes in heteronuclear RNA for corticotrophin-releasing hormone and arginine vasopressin in response to acute stress. J Endocrinol 152:81-89.

Martin DS, Haywood JR (1992) Sympathetic nervous system activation by glutamate injections into the paraventricular nucleus. Brain Res 577:261-267.

Martin DS, Haywood JR (1993) Hemodynamic responses to paraventricular nucleus disinhibition with bicuculline in conscious rats. Am J Physiol 265:H1727-H1733.

Martin DS, Segura T, Haywood JR (1991) Cardiovascular responses to bicuculline in the paraventricular nucleus of the rat. Hypertension 18:48-55.

Morgan JL, Curran T (1991) Stimulus-transcription coupling in the nervous system: involvement of the inducible proto-oncogenes fos and jun. Annu Rev Neurosci 14:421-451.

Nicholas AP, Pieribone V, Hökfelt T (1993) Distributions of mRNAs for alpha-2 adrenergic receptor subtypes in rat brain: an in situ hybridization study. J Comp Neurol 328:575-594.

Oliver C, Jezova D, Grino M, Paulmyer-Lacroix O, Boudouresque F, Joanny P (1996) Excitatory amino acids and the hypothalamicpituitary-adrenal axis. In: Excitatory amino acids. Their role in neuroendocrine function (Brann DW, Mahesh VB, eds), pp 167-185. New York: CRC.

Patchev VK, Karalis K, Chrousos GP (1994) Effects of excitatory amino acid transmitters on hypothalamic corticotropin-releasing hormone $(\mathrm{CRH})$ and arginine-vasopressin (AVP) release in vitro: implications in pituitary-adrenal regulation. Brain Res 633:312-316.

Plotsky PM (1987) Facilitation of immunoreactive corticotropinreleasing factor secretion into the hypophysial-portal circulation after 
activation of catecholaminergic pathways or central norepinephrine injection. Endocrinology 121:924-930.

Plotsky PM, Otto S, Sutton S (1987) Neurotransmitter modulation of corticotropin releasing factor secretion into the hypophysial-portal circulation. Life Sci 41:1311-1317.

Plotsky PM, Cunningham Jr ET, Widmaier EP (1989) Catecholaminergic modulation of corticotropin-releasing factor and adrenocorticotropin secretion. Endocr Rev 10:437-458.

Rivier C, Vale W (1983) Interaction of corticotropin-releasing factor and arginine vasopressin on adrenocorticotropin secretion in vivo. Endocrinology 113:939-942.

Roland BL, Sawchenko PE (1993) Local origins of some GABAergic projections to the paraventricular and supraoptic nuclei of the hypothalamus in the rat. J Comp Neurol 332:123-143.

Rosin DL, Talley EM, Lee A, Stornetta RL, Gaylinn BD, Guyenet PG, Lynch KR (1996) Distribution of alpha 2C-adrenergic receptor-like immunoreactivity in the rat central nervous system. J Comp Neurol 372:135-165.

Sands SA, Morilak DA (1999) Expression of alpha1D adrenergic receptor messenger RNA in oxytocin- and corticotropin-releasing hormonesynthesizing neurons in the rat paraventricular nucleus. Neuroscience 91:639-649.

Saper CB, Levisohn D (1983) Afferent connections of the median preoptic nucleus in the rat: anatomical evidence for a cardiovascular integrative mechanism in the anteroventral third ventricular (AV3V) region. Brain Res 288:21-31.

Sawchenko PE, Swanson LW (1981) Central noradrenergic pathways for the integration of hypothalamic neuroendocrine and autonomic responses. Science 214:685-687.

Sawchenko PE, Swanson LW (1983) The organization of forebrain afferents to the paraventricular and supraoptic nuclei of the rat. J Comp Neurol 218:121-144.

Sawchenko PE, Cunningham ET, Mortrud MT, Pfeiffer SW, Gerfen CR (1990) Phaseolus vulgaris-leucoagglutinin anterograde axonal transport technique. In: Methods in neuroscience, Vol 3 (Conn PM, ed), pp 247-260. New York: Academic.

Simmons DM, Arriza JL, Swanson LW (1989) A complete protocol for in situ hybridization of messenger RNAs in brain and other tissues with radiolabeled single-stranded RNA probes. J Histotechnol 12:169-181.

Soltis RP, Cook JC, Gregg AE, Sanders BJ (1997) Interaction of GABA and excitatory amino acids in the basolateral amygdala: role in cardiovascular regulation. J Neurosci 17:9367-9374.

Swanson LW, Kuypers HG (1980) The paraventricular nucleus of the hypothalamus: cytoarchitectonic subdivisions and organization of projections to the pituitary, dorsal vagal complex, and spinal cord as demonstrated by retrograde fluorescence double-labeling methods. J Comp Neurol 194:555-570.

Swanson LW, Sawchenko PE (1983) Hypothalamic integration: organization of the paraventricular and supraoptic nuclei. Annu Rev Neurosci 6:269-324.

Szafarczyk A, Malaval F, Laurent A, Gibaud R, Assenmacher I (1987) Further evidence for a central stimulatory action of catecholamines on adrenocorticotropin release in the rat. Endocrinology 121:883-892.

Tasker JG, Dudek FE (1993) Local inhibitory synaptic inputs to neurons of the paraventricular nucleus in slices of rat hypothalamus. J Physiol (Lond) 469:179-192.

van den Pol AN (1991) Glutamate and aspartate immunoreactivity in hypothalamic presynaptic axons. J Neurosci 11:2087-2101.

van den Pol AN, Trombley PQ (1993) Glutamate neurons in hypothalamus regulate excitatory transmission. J Neurosci 13:2829-2836.

van den Pol AN, Wuarin JP, Dudek FE (1990) Glutamate, the dominant excitatory transmitter in neuroendocrine regulation. Science 250:1276-1278.

van den Pol A, Hermans-Borgmeyer I, Hofer M, Ghosh P, Heinemann S (1994) Ionotropic glutamate-receptor gene expression in hypothalamus: localization of AMPA, kainate, and NMDA receptor RNA with in situ hybridization. J Comp Neurol 343:428-444.

Watts AG, Swanson LW (1989) Diurnal variations in the content of preprocorticotropin-releasing hormone messenger ribonucleic acids in the hypothalamic paraventricular nucleus of rats of both sexes as measured by in situ hybridization. Endocrinology 125:1734-1738.

Yang Z, Copolov DL, Lim AT (1995) Glutamate enhances the adenylyl cyclase-cAMP system-induced beta-endorphin secretion and POMC mRNA expression in rat hypothalamic neurons in culture: NMDA receptor-mediated modulation. Brain Res 692:129-136. 